\title{
Sputum induction leads to a decrease of exhaled nitric oxide unrelated to airflow
}

\author{
J. Beier, K.M. Beeh, O. Kornmann, R. Buhl
}

Sputum induction leads to a decrease of exhaled nitric oxide unrelated to airflow. J. Beier, K. M. Beeh, O. Kornmann, R. Buhl. C ERS Journals Ltd 2003.

ABSTRACT: Measurement of exhaled nitric oxide (eNO) and analysis of induced sputum are both established noninvasive methods for studying airway inflammation in asthma. Both methods are often used sequentially within short time frames. The aim of the present study was to evaluate the influence of sputum induction on eNO in adults and to follow the kinetics of airway eNO production after induction in relation to forced expiratory volume in one second (FEV1).

eNO and FEV1 were measured in 41 adult patients (aged 29 (range 23-50) yrs, 56\% male) with asymptomatic atopy or mild asthma (mean FEV1 $97.2 \pm 3 \%$ predicted) prior to and immediately after sputum induction with hypertonic saline (4\%). Sputum induction with isotonic saline was also performed in 13 subjects (control group). Repeatability of eNO decrease after sputum induction was also studied in 27 patients on separate occasions and kinetics of eNO production after sputum induction were followed over $24 \mathrm{~h}$ in another 10 patients.

Sputum induction with hypertonic, but not isotonic, saline led to a marked decrease in eNO (log) immediately after the procedure (pre: $3.85 \pm 0.13$ parts per billion (ppb); post: $3.24 \pm 0.14 \mathrm{ppb})$. This decrease was shown to be highly reproducible and not related to a fall in FEV1 following sputum induction. While FEV1 returned to baseline within $1 \mathrm{~h}$, decreased eNO levels were observed over $4 \mathrm{~h}$ and returned to baseline after $24 \mathrm{~h}$.

Hypertonic saline sputum induction leads to a prolonged reduction in exhaled nitric oxide in adult atopics that is reproducible within subjects and not related to a reduction in airflow following sputum induction. This methodological interference should be taken into account when sputum induction and exhaled nitric oxide measurements are performed in the same subject.

Eur Respir J 2003; 22: 354-357.
Pulmonary Dept, Internal Medicine, University Hospital, Mainz, Germany.

Correspondence: J. Beier

Pulmonary Dept, Internal Medicine

University Hospital

Langenbeckstr. 1

55131 Mainz

Germany

Fax: 496131175661

E-mail: j.beier@3-med.klinik.uni-mainz.de

Keywords: Induced sputum

methodology

nitric oxide

repeatability

Received: December 192002

Accepted after revision: April 102003
Induced sputum and measurement of exhaled nitric oxide (eNO) are both noninvasive methods to assess airway inflammation [1]. In clinical or scientific settings, these two methods are often used in the same individual on the same day and sometimes even repeatedly. Thus far, a single study has addressed the influence of sputum induction on eNO levels and shown a reduction of eNO shortly after the procedure [2]. However, possible underlying mechanisms have not been addressed and, in particular, the influence of reduced airflow after sputum induction has not been taken into account. Therefore, the following study was performed to analyse the short- and long-term effects of sputum induction on eNO in relation to pulmonary function and the repeatability of these changes.

\section{Methods}

\section{Patients}

The study population consisted of 41 volunteers with a history of atopy (positive skin-prick test/radioallergosorbent test (RAST) to at least one common aeroallergen). These were 17 asymptomatic patients, 14 mild asthmatics (provocative concentration of methacholine causing a $20 \%$ fall in the forced expiratory volume in one second (PC20, FEV1)
$<8 \mathrm{mg} \cdot \mathrm{mL}^{-1}$ ), and 10 patients with allergic rhinitis. All subjects were nonsmokers showing no signs of acute upper or lower respiratory infection at the time of measurements. Only two of the asthmatic subjects were treated with low-dose inhaled corticosteroids (ICS) that had remained at a constant level for the last 3 months. All subjects were informed about the purpose of the investigation and gave written informed consent. The study was approved by the local ethics committee.

\section{Sputum induction}

Sputum induction was performed according to a method described previously [3]. The output of the nebuliser used was up to $6 \mathrm{~mL} \cdot \mathrm{min}^{-1}$.

\section{Pulmonary function tests}

Spirometry was performed using the Jaeger Masterscope $\mathbb{R}$ spirometry system (Jaeger, Wuerzburg, Germany) according to American Thoracic Society (ATS) guidelines [4].

\section{Measurement of exhaled nitric oxide}

eNO was measured according to standard protocols [5] with a chemiluminescence analyser (ECOmedics, Duernten, 
Switzerland). Briefly, after a deep inhalation of nitric oxide (NO)-free air, subjects performed a single slow exhalation through a mouthpiece against a resistance, which maintained a steady expiratory flow of $50 \mathrm{~mL} \cdot \mathrm{s}^{-1}$ according to ATS guidelines [5]. eNO values were measured at the plateau of the end-exhaled reading and expressed in parts per billion (ppb).

\section{Influence of sputum induction on exhaled nitric oxide}

eNO was measured prior to $(\sim 10 \mathrm{~min})$ and immediately after ( $5 \mathrm{~min}$ ) sputum induction with $4 \%$ hypertonic saline in all 41 subjects. A total of 13 subjects also underwent sputum induction with isotonic saline $(0.9 \% \mathrm{NaCl})$.

Time course of exhaled nitric oxide after sputum induction

In addition, 10 patients underwent repeated measurements of eNO and lung function at determined time points after sputum induction (pre, post, $30 \mathrm{~min}, 1,2,3,4$ and $24 \mathrm{~h}$ ).

\section{Repeatability of decrease of exhaled nitric oxide after} sputum induction

Repeatability of sputum induction-related changes of eNO was studied in 27 patients on two separate occasions (3-8 weeks apart) with similar baseline conditions (daytime, no active or passive smoking, allergen exposure and absence of respiratory tract infection).

\section{Statistical analysis}

Statistical analysis was performed using the STATA S.O. intercooled software package (Stata Corp., TX, USA) for personal computers. As eNO values were skewed and lognormally distributed all eNO values were log-transformed for statistical analysis. Data are presented as mean values (FEV1, eNOlog) with mean \pm SEM. Pre-/post-analysis, time course of eNO and FEV1 and comparison of effect size of either isotonic or hypertonic saline inhalation was performed by repeated analysis of variance (ANOVA) using Bonferroni's correction. Correlations were calculated by Spearman's rank correlational analysis (rho). Reproducibility was determined using intra-class correlation-coefficient $\left(\mathrm{R}_{\mathrm{i}}\right)$ and coefficient of repeatability $(C R=2 \mathrm{SD}$ of the mean difference of repeated measurements) [6]. Results were graphically reported as proposed by BLAND and ALTMAN [7]. The CR represents the limits of agreement within which $95 \%$ of the differences of repeated measurements were expected to be. A p $<0.05$ was considered to be statistically significant.

\section{Results}

Influence of hypertonic saline sputum induction on exhaled nitric oxide

Sputum induction with hypertonic saline led to a significant decrease of eNOlog $5 \mathrm{~min}$ after the procedure (pre: eNOlog $3.85 \pm 0.13$ ppb; post: eNOlog 3.24 $\pm 0.14 \mathrm{ppb} ; \mathrm{p}<0.001)$ and FEV1 (pre: $97.23 \%$ predicted; post: $89.9 \pm 3 \%$ pred; $\mathrm{p}<0.001$ ). There was no correlation of the individual change in eNO with changes in FEV1 (rho=0.13, $\mathrm{p}=0.41$ ). There were no differences observed in the individual groups and in the two patients on constant treatment with ICS.

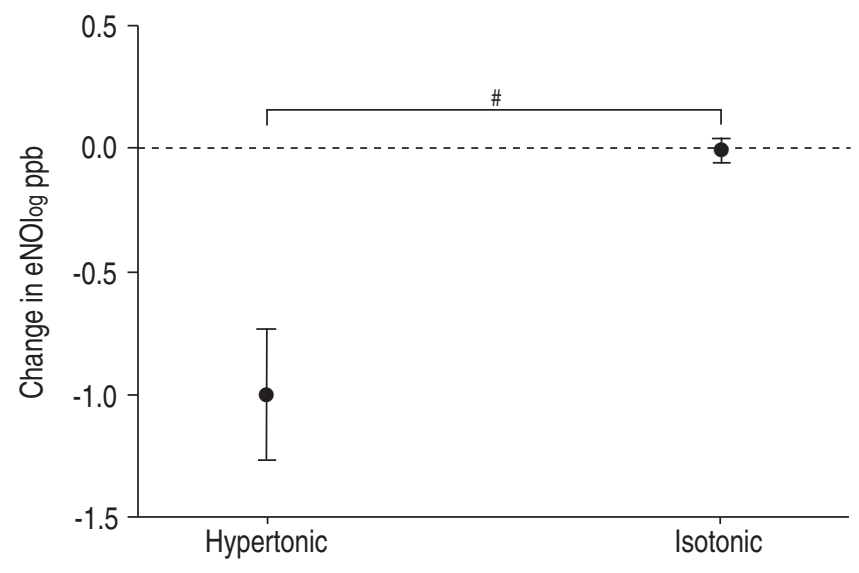

Fig. 1.-Changes in exhaled nitric oxide (eNO)log after sputum induction with hypertonic and isotonic saline solution. Data are presented as mean difference \pm SEM, $n=13$. ${ }^{\#}: \mathrm{p}=0.001$.

Influence of isotonic saline sputum induction on exhaled nitric oxide

Following induction with isotonic saline, there was no change in eNOlog (pre: $4.1 \pm 0.19 \mathrm{ppb}$; post: $4.1 \pm 0.2 \mathrm{ppb}$; $\mathrm{p}=0.92$ ) or FEV1 (pre: $97.3 \pm 3 \%$ pred; post: $96.9 \pm 2.8 \%$ pred; $\mathrm{p}=0.67) 5 \mathrm{~min}$ after induction. The magnitude of change in eNOlog in these 13 patients was significantly greater after hypertonic saline challenge (fig. 1).

Time course of exhaled nitric oxide after sputum induction

Sputum induction led to a prolonged reduction of eNOlog that was statistically different from baseline up to $4 \mathrm{~h}$ after induction $(\mathrm{p}<0.04$, all comparisons). After $24 \mathrm{~h}$, eNO levels had returned to baseline values (pre: $100 \% ; 24 \mathrm{~h}$ : $102 \pm 1.2 \%$; $\mathrm{p}=0.91$ ). In contrast, there was only a mild decrease in FEV1 immediately after sputum induction (pre: 100\%; post: $94 \pm 2.6 \% ; \mathrm{p}=0.05)$, which had already normalised within the first hour ( $100 \pm 2 \%$ compared to baseline FEV1; $p=0.97)$ (fig. 2).

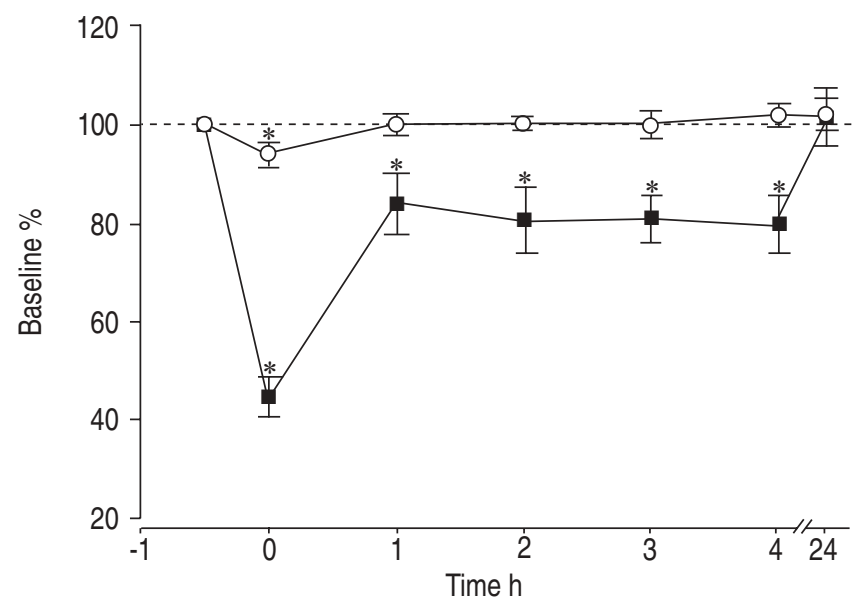

Fig. 2. - Time course of exhaled nitric oxide $(\boldsymbol{\square})$ and forced expiratory volume in one second $(\bigcirc)$ measured before, directly after and 1 , $2,3,4$ and $24 \mathrm{~h}$ after sputum induction with hypertonic saline $(\mathrm{n}=10)$. *: $\mathrm{p}<0.04$ compared to baseline. 


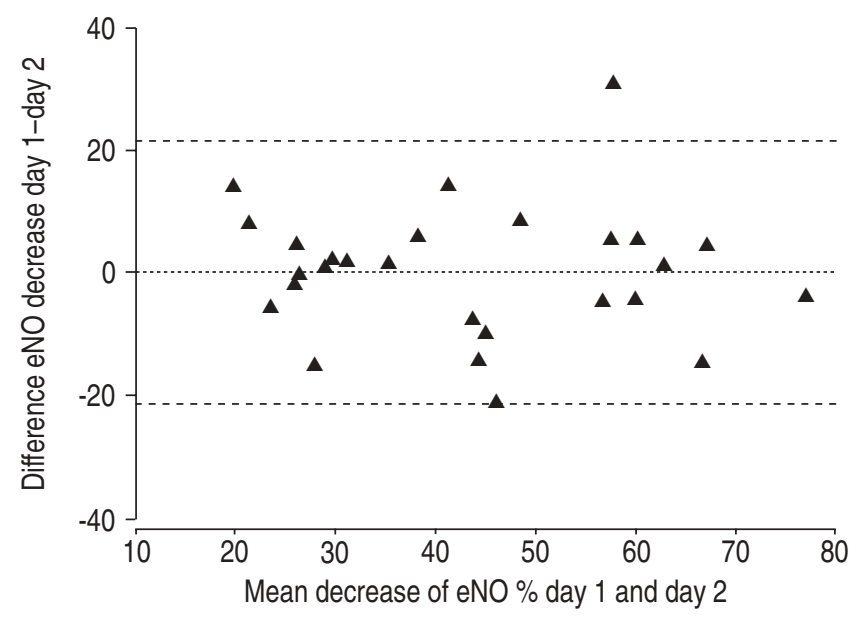

Fig. 3. - Repeatability of exhaled nitric oxide (eNO) reduction after sputum induction with hypertonic saline measured on two different occasions (day 1 and day 2 ). $n=27$, dashed lines represent \pm 2 SD.

\section{Repeatability of induction-related changes of exhaled nitric oxide}

There was a similar decrease of eNO 5 min after induction obtained on two different occasions (mean decrease from baseline day 1: $43.4 \pm 3.3 \%$; day $2: 43.2 \pm 3.4 \%$; $=0.98$ ). The intra-class correlation coefficient of repeated measurements was $\mathrm{R}_{\mathrm{i}}=0.81$ with a $\mathrm{CR}$ of $21 \%$. (fig. 3 ).

\section{Discussion}

As sputum induction and eNO are methods often used in combination, this study was performed to systemically analyse a possible interference of sputum induction and eNO measurements.

In the present study, eNO decreased dramatically after sputum induction with hypertonic saline. This effect lasted $\geqslant 4-6 \mathrm{~h}$ and did not seem to be related to parameters of airway obstruction, e.g. FEV1. Moreover, the inductionrelated drop of eNO was found to be highly reproducible in individual subjects.

Although an initial contribution of induction-related airway obstruction to eNO decrease cannot be completely excluded [8], the time course of eNO after sputum induction derived from this study clearly suggests that the prolonged drop in eNO is independent of airway calibre. This observation is in agreement with published studies, in which the influence of bronchoconstriction on eNO is at least controversial. While some authors have reported decreased eNO levels after histamine or adenosine challenge [9], others have clearly shown that neither acute bronchoconstriction, achieved by methacholine, nor acute bronchodilatation following use of $\beta$-agonists affected the levels of eNO in mild asthmatic patients [10].

This observation raises the following question. Which mechanisms underlie the observed drop in eNO after sputum induction? First, repeated spirometry manoeuvres have been shown to affect eNO levels in healthy or asthmatic subjects [11]. However, in the present study, spirometry alone did not decrease eNO levels (data not shown). Secondly, osmotic changes in bronchial epithelium evoked by inhalation of hypertonic saline could also affect eNO. A hypertonic saline-induced fall in eNO unrelated to bronchoconstriction may be due to an effect on the NO signal-transduction pathway: airway epithelial cells express the inducible isoform of NO synthase (NOS) [12] and are sensitive to osmotic stimuli. MANISCALCO et al. [13] have shown recently that inhalation of hypo-osmotic water (undistilled water) decreases NO levels in exhaled air with no effect on airway calibre, whereas inhalation of isotonic saline had no effect on eNO, which is fully compliant with the findings of the present study [13]. Although Hogman et al. [14] showed that NO release was different in healthy compared to asthmatic subjects after hyperosmolar challenge with mannitol, the present authors did not see any differences when comparing the individual groups (data not shown).

The discussion concerning airflow obstruction as the main reason for the decreased eNO values is controversial. In a second set of experiments it was shown that in contrast to FEV1, which recovered quickly after an initial decrease following sputum induction, eNO levels remained significantly different from baseline much longer and returned to baseline values after $24 \mathrm{~h}$, again contradicting the argument of a causal role of bronchoconstriction for eNO reduction after sputum induction.

Finally, increased mucus production through hypertonic saline inhalation has to be considered as a possible cause for eNO decrease after sputum induction. Mucus accumulation could inhibit NO diffusion from bronchial epithelial cells, therefore resulting in decreased eNO levels [15]. From the authors' point of view, this is the most likely explanation of the findings and this is also supported by the clinical observation of prolonged mucus production and related cough in the majority of patients.

In conclusion, the present study demonstrates a reproducible, highly significant and prolonged fall of exhaled nitric oxide levels due to sputum induction with hypertonic saline that was unrelated to airflow obstruction. This observation has important implications for the interpretation of many studies that use both techniques to monitor airway inflammation.

\section{References}

1. Kharitonov S, Yates DH, Barnes PJ. Inhaled gluccocorticoids decrease nitric oxide in exhaled air of asthmatic patients. Am J Respir Crit Care Med 1996; 153: 454 457.

2. Piacentini GL, Bodini A, Costella S, Vicentini L, Suzuki Y, Boner AL. Exhaled nitric oxide is reduced after sputum induction in asthmatic children. Pediatr Pulmonol 2000; 29: 430-433.

3. Pizzichini E, Pizzichini MMM, Efthimiadis A, et al. Indices of airway inflammation in induced sputum: reproducibility and validity of cell and fluid-phase measurements. $\mathrm{Am}$ J Respir Crit Care Med 1996; 154: 308-317.

4. American Thoracic Society. Standardization of Spirometry1987 Update. Am Rev Respir Dis 1987; 136: 1285-1298.

5. Recommendations for standardized procedures for the online and off-line measurement of exhaled lower respiratory nitric oxide and nasal nitric oxide in adults and children1999. This official statement of the American Thoracic Society was adopted by the ATS Board of Directors, July 1999. Am J Respir Crit Care Med 1999; 160: 2104 2117.

6. Chinn S. Repeatability and method comparison. Thorax 1991; 46: 454- 456.

7. Bland JM, Altman DC. Statistical methods for assessing agreement between two methods of clinical measurement. Lancet 1986; 1: 307-310.

8. Piacentini GL, Bodini A, Peroni DG, Miraglia del Giudice M Jr, Costella S, Boner AL. Reduction in exhaled nitric oxide immediately after methacholine challenge in asthmatic children. Thorax 2002; 57: 771-773. 
9. de Gouw HW, Hendriks J, Woltman AM, Twiss IM, Sterk PJ. Exhaled nitric oxide (NO) is reduced shortly after bronchoconstriction to direct and indirect stimuli in asthma. Am $J$ Respir Crit Care Med 1998; 158: 315-319.

10. Silkoff PE, Wakita S, Chatkin J, et al. Exhaled nitric oxide after beta2-agonist inhalation and spirometry in asthma. Am J Respir Crit Care Med 1999; 159: 940-944.

11. Deykin A, Massaro AF, Coulston E, Drazen JM, Israel E. Exhaled nitric oxide following repeated spirometry or repeated plethysmography in healthy individuals. $\mathrm{Am}$ J Respir Crit Care Med 2000; 161: 1237-1240.

12. Dweik RA, Laskowski D, Abu-Soud HM, et al. Nitric oxide synthesis in the lung. Regulation by oxygen through a kinetic mechanism. J Clin Invest 1998; 101: 660-666.

13. Maniscalco M, Vatrella A, Cremona G, Carratu L, Sofia M Exhaled nitric oxide after inhalation of isotonic and hypotonic solutions in healthy subjects. Clin Sci (Lond) 2001; 101: 645-650.

14. Hogman M, Ludviksdottir D, Anderson SD, et al. Inhaled mannitol shifts exhaled nitric oxide in opposite directions in asthmatics and healthy subjects. Respir Physiol 2001; 124: 141-150.

15. Balfour-Lynn IM, Laverty A, Dinwiddie R. Reduced upper airway nitric oxide in cystic fibrosis. Arch Dis Child 1996; 75: 319-322. 